\title{
LUGARES POLÍTICOS: ¿Y SI EL OTRO NO ESTUVIERA ALLÍ?1
}

\author{
LUGARES POLÍTICOS: E SE OUTRO NÃO ESTIVER AÍ?
}

\section{POLITICAL PLACES: AND WHAT IF THERE BE NO OTHER?}

\author{
Jorgelina Tallei \\ Universidade Federal da Integração Latino-Americana - UNILA²
}

\begin{abstract}
Resumen
El nombre que origina este artículo se relaciona con la in/visibilización de temáticas interculturales en el ámbito de las políticas públicas educativas. Cabe aclarar que al referirme a temáticas interculturales lo hago desde el lugar de temáticas transfronterizas. Este trabajo no pretende ser exhaustivo en su análisis, ya que otros temas deberían ser considerados y excedería con mucho el propósito. Por tanto, el recorte obedece al propósito de realizar un recorrido sintético sobre los documentos oficiales que colocaron en pauta propuestas interculturales de manera general en los tres países de la Triple Frontera, Argentina, Brasil y Paraguay. Los documentos analizados son: la Ley de Directrices y Bases de Educación Nacional n 9.394/1996 (Brasil); los Parámetros Curriculares Nacionales (PCN) (Brasil); las Directrices Curriculares para la enseñanza básica (Brasil); el Informe de la formación docente en Argentina (Argentina); la modalidad de educación intercultural bilingüe en el sistema educativo nacional (Argentina); la Ley General de Educación 1264/98 (Paraguay); la Ley de Educación Superior y el Estatuto del Educador Profesional y, por último, la Ley 1725/2001 (Paraguay).
\end{abstract}

Palabras claves: interculturalidad, formación docente, política pública.

\section{Resumo}

O nome que dá origem a este artigo está relacionado à in/visibilidade de questões interculturais no campo das políticas públicas de educação. Deve-se notar que, ao se referir a questões interculturais, eu faço isso a partir do lugar das questões transfronteiriças. Este trabalho não pretende ser exaustivo em sua análise, uma vez que outras questões devem ser consideradas e excedem em muito o propósito deste trabalho. Portanto, o corte deve-se ao propósito de fazer uma síntese dos documentos oficiais que colocaram propostas interculturais na agenda de maneira geral, na Tríplice Fronteira: Brasil, Argentina e Paraguai. Os documentos analisados são:

\footnotetext{
${ }^{1}$ La referencia ¿y si el otro no estuviera ahí? es de inspiración del artículo del autor Carlos Skliar (2002).

2 Possui Licenciatura em Letras pela Universidad Nacional de Rosario (2003), Mestrado em Letras - Língua Espanhola e Literatura Espanhola e Hispano-Americana pela Universidade de São Paulo (2010) e Mestrado Profissionalizante na Área de Novas Tecnologias, pelo Instituto Universitario de Posgrado (Espanha). Doutora em Educação no Programa Latino-americano de Educação (FAE) da Universidade Federal de Minas Gerias (UFMG). Atualmente é Professora de Língua Espanhola como língua adicional na Universidade Federal da Integração Latino-Americana (UNILA) no Ciclo Comum de Estudos. E-mail: jorgelina.tallei@unila.edu.br.
} 
a Lei de Diretrizes e Bases da Educação Nacional no 9.394 / 1996 (Brasil); os Parâmetros Curriculares Nacionais (PCN) (Brasil); as Diretrizes Curriculares para a educação básica (Brasil); o Relatório de Treinamento de Professores na Argentina (Argentina); a modalidade de educação intercultural bilíngue no sistema nacional de educação (Argentina); a Lei Geral de Educação 1264/98 (Paraguai); a Lei do Ensino Superior e o Estatuto do Educador Profissional e, finalmente, a Lei 1725/2001 (Paraguai).

Palavras-chave: Interculturalidade; Formação Docente; Política Pública.

\section{Abstract}

The name that gave rise to this article is related to the in / visibility of intercultural issues in the field of public education policies. It should be noted that when referring to intercultural issues, I do so from the point of view of cross-border issues. This work is not intended to be exhaustive in its analysis, since other issues should be considered and far exceed its purpose. Therefore, it limits itself to the aim of summarizing the official documents that put intercultural proposals on the agenda in general, at the Triple Frontier: Brazil, Argentina and Paraguay. The documents analyzed are: the Law on Guidelines and Bases of National Education No. 9,394 / 1996 (Brazil); the National Curricular Parameters (NCP) (Brazil); the Curricular Guidelines for Basic Education (Brazil); the Teacher Training Report in Argentina (Argentina); the modality of bilingual intercultural education in the national education system (Argentina); the General Education Law 1264/98 (Paraguay); the Law of Higher Education and the Statute of the Professional Educator, and finally, Law 1725/2001 (Paraguay).

Keywords: Interculturality; Teacher Training; Public Policy.

\section{INTRODUCCIÓN}

\section{LA FORMACIÓN DOCENTE Y EL CONCEPTO DIVERSIDAD/INTERCULTURALIDAD EN LOS DOCUMENTOS OFICIALES}

En 1996, la Ley de Directrices y Bases de Educación Nacional n 9.394/1996 reafirma la necesidad de una formación docente permanente. GATTI (2008) asevera que en la última década este tema entra en la pauta mundial y esto se debe a la presión instituida por el mundo del trabajo. En este contexto, la cuestión intercultural entró en escena. De acuerdo con Fleuri, F. (2001), fue en esta década cuando se comenzó a valorizar la cultura popular en el ámbito educativo desde los movimientos sociales, del campo y de las luchas populares. Los movimientos sociales adquieren en esta fundamental importancia en la historia de las políticas educativas interculturales en América Latina.

En relación con los documentos oficiales, es posible afirmar que, con sus aciertos y desaciertos, los Parámetros Curriculares Nacionales (PCN), texto publicado en 1990, se presenta como uno de los primeros documentos en dar protagonismo a los temas interculturales (CANDAU, 2009) en territorio brasilero. 
De hecho, los estudios sobre interculturalidad han venido creciendo de manera constante entre los años de 1990 y 2000 en América Latina. En los PCN (1996) hay un subcapítulo destinado a la discusión del tema:

As adaptações curriculares previstas nos níveis de concretização apontam a necessidade de adequar objetivos, conteúdos e critérios de avaliação, de forma a atender a diversidade existente no País. Essas adaptações, porém, não dão conta da diversidade no plano dos indivíduos em uma sala de aula. [...] atender necessidades singulares de determinados alunos é estar atento à diversidade: é atribuição do professor considerar a especificidade do indivíduo, analisar suas possibilidades de aprendizagem e avaliar a eficácia das medidas adotadas. (PCN, 1996, p.63).

Como afirma CANEN (2000), es importante mencionar que los PCN se diseñan en el contexto de otro documento denominado: Pluralidade Cultural, de 1997. La autora, además, señala que el documento se divide en dos partes en la que se presentan contradicciones referentes al análisis sobre la pluralidad cultural.

El documento parece tratar la cuestión de la identidad como única, en contradicción con el propio significado del concepto pluricultural. CANEN (2000) también apunta que el documento se refiere a la diversidad de Brasil desde lo macro, desconsiderando las especificidades. En el mismo sentido, el apartado dedicado en los PNC determina que se tengan en cuenta las diversidades existentes en el país, pero que recae en cada docente la responsabilidad de atender las necesidades específicas de cada uno de los alumnos/as en el aula.

Una revisión por las Diretrizes Curriculares Nacionais da Educação Básica (2013) se aproxima al tema intercultural desde la valorización de los pueblos indígenas:

Da confluência dos princípios e direitos da educação escolar indígena, traduzidos no respeito à sociodiversidade; na interculturalidade; no direito de uso de suas línguas maternas e de processos próprios de aprendizagem; na articulação entre os saberes indígenas e os conhecimentos técnico-científicos - com os princípios da formação integral, visando à atuação cidadã no mundo do trabalho, da sustentabilidade socioambiental e do respeito à diversidade dos sujeitos da educação profissional e tecnológica, surge a possibilidade de uma educação profissional indígena que possa contribuir para a reflexão e construção de alternativas de gerenciamento autônomo dos territórios indígenas, de sustentação econômica, de segurança alimentar, de saúde, de atendimento às necessidades cotidianas, entre outros. (BRASIL, 2013, p. 222).

La cita cobra sentido al colocar el tema intercultural en términos de derechos, como el derecho a la lengua y a los procesos propios de aprendizaje, en consonancia con el diseño de una interculturalidad ciudadana. El documento también especifica la 
responsabilidad del estado brasilero en la formación docente de indígenas para su actuación en las escuelas:

Formar indígenas para serem professores e gestores das mais de 2.836 escolas localizadas em terras indígenas é hoje um dos principais desafios e prioridades para a consolidação de uma Educação Escolar Indígena pautada pelos princípios da diferença, da especificidade, do bilinguismo e da interculturalidade. A formação de professores indígenas - docentes e gestores - é, portanto, um compromisso público do Estado brasileiro que deve ser garantido pelos sistemas de ensino e suas instituições formadoras. A formação inicial deve ocorrer em cursos específicos de licenciaturas e pedagogias interculturais ou complementarmente, quando for o caso, em outros cursos de licenciatura específica ou, ainda, em cursos de magistério indígena de nível médio na modalidade normal (BRASIL, 2013, p. 336/337).

Y más adelante, añade:

Desse modo, não se pode admitir a existência de qualquer forma de distinção ou discriminação que embarace ou impeça o acesso à Educação Básica de crianças, adolescentes ou jovens itinerantes, filhos ou não de trabalhador circense. O Plano Nacional de Educação em Direitos Humanos de 2006 reconhece a educação como um direito humano e ao mesmo tempo "um meio privilegiado na promoção dos direitos humanos", sendo, portanto, a garantia desse direito fundamental para a própria dignidade humana. Cabe destacar que o Brasil é signatário da Convenção 169, da Organização Internacional do Trabalho, cujo art. 14, item 1, faz menção aos povos nômades e agricultores itinerantes. (BRASIL, 2013, p. 398).

Además, se les asegura la condición de matrícula y la protección ante cualquier tipo de discriminación, en la consideración del acceso a la educación como un derecho humano.

Ahora bien, más allá de estos enunciados, resulta pertinente señalar que sobre la formación docente permanente en el área de frontera, es decir, en contextos interculturales, no haré referencia a la problemática indígena, ya que apenas existen estudios en Foz de Iguazú que den cuenta de este tema.

Como afirma FLEURI (2004), tratar la interculturalidad en la clase requiere una apuesta importante y fundamental para desarrollar conceptos que trabajen los conflictos cotidianos superando las estructuras socioculturales que generan discriminación y exclusión.

\section{LOS DOCUMENTOS OFICIALES Y UNA EDUCACIÓN INTERCULTURAL EN ARGENTINA}

Del lado argentino, entre los gobiernos de Néstor Kirchner y Cristina Fernández de Kirchner (2003-2015), es cuando parece haber una mayor preocupación con el tema 
intercultural, en materia de educación, si bien ya habían entrado en debate en la década de los 90.

Argentina sanciona en 1994 el derecho constitucional a la Educación Intercultural Bilingüe. Este derecho está relacionado fundamentalmente a las políticas inclusivas en favor de los derechos de los pueblos originarios. Se asocian de esta manera los términos interculturalidad y bilingüismo en la legislación en lo referente a los pueblos originarios. El Estado se propone desde entonces dar voz y reconocimiento en los diversos ámbitos a las comunidades de los diferentes pueblos originarios de este país. Para Soria (2010):

En Argentina, la transformación educativa fue el concepto que sintetizó las reformas estructurales en este ámbito durante los noventa y el punto de inflexión que permitió la resignificación de ciertas representaciones y discursos en relación con la diferencia cultural, en general, y "lo indígena", en particular. Si en sus momentos fundacionales la institución educativa cumplió una función clave en la construcción de una nación que se pretendía blanca y homogénea, en la definición de la diferencia cultural como "barbarie" el nuevo proyecto político, configurado a fin de siglo, favoreció nuevos modos de integración y tratamiento de esa diferencia antes excluida y estigmatizada. Tanto en el diseño de políticas como en los espacios escolares, comenzaron a instalarse discursos y prácticas cuya tendencia era la aceptación del otro, la atención a la diversidady el reconocimiento de la diferencia. (SORIA, 2010, p.171).

Otros documentos oficiales son importantes para el desarrollo de las políticas educativas interculturales bilingües: la Resolución N 107 del Consejo Federal de Cultura y Educación (1999), la Resolución no 549 del Ministerio de Educación Ciencia y Tecnología de la República Argentina (2004), la Ley de Educación Nacional nº 26.206 (2006), el Documento para la Modalidad de Educación Intercultural Bilingüe en el Sistema Educativo Nacional del Consejo Federal de Educación (2010) y la Resolución № 105 del Consejo Federal de Cultura y Educación (2010).

En 2006, la Ley Federal de Educación se modifica y se sanciona la Ley $n^{\circ} 26.206$, que en su artículo 17 reconoce cuatro niveles de enseñanza con sus respectivas modalidades:

ARTICULO 17. - La estructura del Sistema Educativo Nacional comprende CUATRO (4) niveles - la Educación Inicial, la Educación Primaria, la Educación Secundaria y la Educación Superior, y OCHO (8) modalidades. A los efectos de la presente ley, constituyen modalidades del Sistema Educativo Nacional aquellas opciones organizativas y/o curriculares de la educación común, dentro de uno o más niveles educativos, que procuran dar respuesta a requerimientos específicos de formación y atender particularidades de carácter permanente o temporal, personales y/o contextuales, con el propósito de garantizar la igualdad en el derecho a la educación y cumplir con las exigencias legales, técnicas y pedagógicas de los diferentes niveles educativos. Son modalidades: la Educación Técnico Profesional, la Educación Artística, la Educación Especial, la Educación Permanente de Jóvenes y Adultos, la Educación 
Rural, la Educación Intercultural Bilingüe, la Educación en Contextos de Privación de Libertad y la Educación Domiciliaria y Hospitalaria. Las jurisdicciones podrán definir, con carácter excepcional, otras modalidades de la educación común, cuando requerimientos específicos de carácter permanente y contextual así lo justifiquen. (ARGENTINA: 2006: p. $3^{3}$ )

Y en el artículo 52 se reconoce la educación intercultural bilingüe desde el marco de la valorización como una interculturalidad para el diálogo resaltando la condición de todos los agentes implicados en el proceso para la construcción de un modelo intercultural de enseñanza. Aquí también se señala que el modelo a desarrollar pretende atender a múltiples contextos y pluralidades y entre sus objetivos se propone:

a) Crear mecanismos de participación permanente de los/las representantes de los pueblos indígenas en los órganos responsables de definir y evaluar las estrategias de Educación Intercultural Bilingüe.

b) Garantizar la formación docente específica, inicial y continua, correspondiente a los distintos niveles del sistema.

c) Impulsar la investigación sobre la realidad sociocultural y lingüística de los pueblos indígenas que permita el diseño de propuestas curriculares, materiales educativos pertinentes e instrumentos de gestión pedagógica.

d) Promover la generación de instancias institucionales de participación de los pueblos indígenas en la planificación y gestión de los procesos de enseñanza y aprendizaje.

e) Propiciar la construcción de modelos y prácticas educativas propias de los pueblos indígenas que incluyan sus valores, conocimientos, lengua y otros rasgos sociales y culturales. (ARGENTINA, 2006, p. 52).

De todas formas, como expone Soria (2010):

La Ley de Educación Nacional, aprobada a fines de 2006, recupera estas nociones como modo de afirmar una política de reconocimiento hacia los pueblos indígenas, pero también para sentar las bases de lo que el Estado entiende como "nuevo" proyecto político y social. En el marco de lo que se postula como una nueva etapa que vendría a superar las políticas neoliberales de los noventa, los principios de respeto de la diversidad, sociedad multicultural e interculturalidad ${ }^{4}$, entre otros, se erigen como ideas clave que permitirían consolidar un Estado y una sociedad diferentes. (SORIA, 2010, p. 168)

La configuración de una nueva política de estado posibilitó el surgimiento de pos títulos y/o carreras docentes que colocaron en debate las pautas interculturales y,

${ }^{3}$ Documento en línea: https:/www.fmmeducacion.com.ar/wp-content/uploads/2018/03/Ley-26026-deEducacion-Nacional.pdf Fecha de consulta: 29 de noviembre de 2018.

${ }^{4}$ Destacado de la autora. 
específicamente, las relacionadas a los pueblos originarios. Entre los postítulos creados se encuentran el denominado "Interculturalidad y enseñanza de español como segunda lengua o extranjera". En este punto vale recordar que en la Argentina se hablan varias lenguas, como el "guaraní, el mapudungun, el quechua, el aymara, el wichi y el qom, y lenguas de inmigración, como el alemán, el árabe, el armenio, el chino, el coreano, el francés, el ídish, el inglés, el italiano, el japonés y el portugués, entre otras." (BEIN, 2017: p.3).

Se destaca como programa de formación en el nivel de posgrado la Tecnicatura Superior en Educación Intercultural bilingüe con mención en lengua quichua, de la Universidad de Santiago del Estero, como la primera propuesta a llevarse a cabo en esa temática.

En el Plan de Estudios de esta carrera ya desde las primeras páginas se hace mención a los conceptos de pluriculturalismo y de plurilingüismo.

En mayo del 2007, la Dirección General de Cultura y Educación de la Provincia de Buenos Aires, coordinada en aquel momento por Adriana Puiggrós, elabora un documento que denomina: Interculturalidad como perspectiva política, social y cultural, donde delinea algunos puntos sobre la educación intercultural. El documento establece desde las primeras páginas que la interculturalidad no ha de concebirse apenas en el ámbito formal escolar, sino que debe extenderse a toda la sociedad.

Por último, cabe destacar como política pública pensada como un proyecto de integración la creación en el año 2017, mediante la Resolución 1657-E/2017, de la primera universidad pública bilingüe, la Universidad Nacional del Alto Uruguay, en la provincia de Misiones.

En su estatuto, el primer objetivo es (2017):

La generación, producción y transmisión del conocimiento e innovaciones científico-tecnológicas, con responsabilidad social y ambiental, para contribuir al desarrollo sustentable del territorio regional y nacional al que pertenece, la cooperación e integración especialmente con países del Mercosur, América Latina y el Caribe. (ARGENTINA: 2017, p.3).

Con la finalidad de incentivar la integración entre América Latina y el Caribe, el cuarto objetivo se propone (2017):

Fortalecer los principios democráticos, el pensamiento crítico, la multiculturalidad, la interdisciplinariedad, respeto por las diferencias y la interacción con la comunidad, propendiendo a una mejor calidad de vida de la sociedad en general. [...] Estructurar sus ejes curriculares con modalidades flexibles y transversales en la tecnología e innovación, las tecnologías de la información y comunicación, el desarrollo sustentable, 
fomentando la actitud asociativa y emprendedora, en el plurilingüismo multicultural e identidad transfronteriza. [...] (ARGENTINA: 2017, p.3).

Para ello, promueve el uso del español y del portugués en los planes de estudios y en la contratación de docentes de ambas lenguas.

\section{LOS DOCUMENTOS OFICIALES Y UNA EDUCACIÓN INTERCULTURAL EN PARAGUAY}

En la Constitución Nacional sancionada en 1992, el capítulo V reconoce a los pueblos originarios como grupos de culturas anteriores a la formación del estado nacional paraguayo. Y el artículo 66, determina que:

Artículo 66 - DE LA EDUCACIÓN Y LA ASISTENCIA: EI Estado respetará las peculiaridades culturales de los pueblos indígenas especialmente en lo relativo a la educación formal. Se atenderá, además, a su defensa contra la regresión demográfica, la depredación de su hábitat, la contaminación ambiental, la explotación económica y la alienación cultural. (PARAGUAY, 1992)

Garantizando, así, una educación formal, aunque sin detallar de qué forma. En cambio, en la ley que determina las directrices de la educación es la Ley General de Educación n¹264, de 1998 sí se especifica vagamente que todo habitante de la República de Paraguay tiene derecho a una educación integral y que esta se realizará en el contexto de la cultura de la comunidad. No obstante, tal como afirma SAFORCADA, F.; VASSILIADES, A. (2011: p. 297):

En las leyes, las definiciones del derecho a la educación son variables y con diversas traducciones a la hora de plantear estrategias para consolidar su vigencia. En algunos casos, el derecho a la educación aparece como derecho de todas las personas (Chile y Colombia) o derecho de cada habitante (Paraguay), desde una concepción individualista, que suele ir de la mano con el rol subsidiario del Estado como mero protector del derecho individual de las personas

Uno de los principales contenidos de la Ley es el reconocimiento al derecho de la formación en las dos lenguas oficiales del país, el castellano y el guaraní. Es el único de los tres países que reconoce esta última como lengua oficial, abogando en sus documentos oficiales por la idea de un país bilingüe e intercultural. Ahora bien, es el único también de los tres países que no presenta una propuesta clara para el desarrollo de una educación intercultural y bilingüe. Las lenguas indígenas forman parte del patrimonio de la cultura de la nación expreso en la Constitución de Paraguay, Capítulo V. Art. 64: p.13 (en línea $\left.{ }^{5}\right):$

5 En línea: http://www.oas.org/juridico/spanish/mesicic2 pry anexo3.pdf Fecha de consulta: 14 de noviembre de 2018. 
Los pueblos indígenas tienen derecho a la propiedad comunitaria de la tierra, en extensión y calidad suficientes para la conservación y el desarrollo de sus formas peculiares de vida. El Estado les proveerá gratuitamente de estas tierras, las cuales serán inembargables, indivisibles, intransferibles, imprescriptibles, no susceptibles, no susceptibles de garantizar obligaciones contractuales ni de ser arrendadas; asimismo, estarán exentas de tributo. Se prohibe la remoción o traslado de su hábitat sin el expreso consentimiento de los mismos.

Y la Ley General de Educación (1264/98) en su artículo nueve, capítulo II, destaca las dos lenguas oficiales del país:

Artículo 9․- Son fines del sistema educativo nacional:

a. el pleno desarrollo de la personalidad del educando en todas sus dimensiones, con el crecimiento armónico del desarrollo físico, la maduración afectiva, la integración social libre y activa;

b. el mejoramiento de la calidad de la educación;

c. la formación en el dominio de las dos lenguas oficiales;

d. el conocimiento, la preservación y el fomento de la herencia cultural, lingüística y espiritual de la comunidad nacional.

Además, esta Ley de educación se vio integrada por la Ley de Lenguas, aprobada en el año 2011, donde se implementa la enseñanza de las dos lenguas oficiales y se crea la Academia de la Lengua Guaraní. Vale mencionar que, según QUIÑONEZ DE BERNAL (2012; p. 12), "Paraguay es un país bilingüe con uso generalizado del guaraní y del castellano, según el Censo de 2002, el 50\% de la población manifiesta hablar las dos lenguas guaraní y español”6.

Es el Ministerio de Educación y Cultura de Paraguay quien centraliza la planificación de las propuestas de políticas educativas.

En 1993, con la sanción de la reforma educativa, la formación docente permanente se coloca entre las prioridades del Estado, que en Paraguay es de responsabilidad de las universidades y de los institutos terciarios ${ }^{7}$. En este sentido, coincide con la organización establecida en Argentina, mientras que en Brasil la responsabilidad es apenas de las universidades.

El Ministerio de Educación de Paraguay participa de la oferta de formación permanente por medio del Instituto Superior de Educación Dr. Raúl Peña y del Sistema Nacional de Actualización Docente.

Se reconoce la labor de la formación docente permanente como la articulación entre la formación inicial y la formación en servicio, según el Decreto 468/2003: "Art. 3ºLa formación continua de los educadores comprende la formación docente inicial y la

\footnotetext{
${ }^{6}$ Este dato suministrado por el censo requiere de estudios más profundos sobre los usos de la lengua en el país.

7 Institutos Superiores de carácter no universitario.
} 
formación docente en servicio. Podrá ser realizada por los institutos de formación docente, institutos superiores y universidades". La formación docente inicial y la formación docente en servicio se rigen por la Ley General de Educación (1264/98), la Ley de Educación Superior y el Estatuto del Educador Profesional (Ley 1725/2001).

En el 2007 se creó la Dirección General de Educación Escolar Indígena y diez años después se pusieron en marcha las Especializaciones en Educación Intercultural Bilingüe y en Educación de Personas Jóvenes y Adultas implantadas por el Ministerio de Educación de Paraguay en colaboración con la Organización de Estados Iberoamericanos (OEI) y financiadas por el Fondo Nacional de Inversión Pública y Desarrollo (FONACIDE).

Según el sitio ${ }^{8}$ de la OEI de Paraguay:

Aprobadas por Resoluciones № 26300/16 y № 28136/16, respectivamente, estos programas de formación han sido pensados, desarrollados y elaborados partir de las necesidades del país, por lo cual se las identifican como particularmente innovadoras e inéditas.La Especialización en Educación Intercultural Bilingüe tiene por objeto responder a las exigencias educativas actuales de los docentes del contexto educativo indígena y garantizar una educación escolar que fortalezca la identidad y promueva la participación de los Pueblos Indígenas en la sociedad nacional paraguaya en igualdad de condiciones.

En los documentos oficiales mencionados se alude al concepto de formación docente en servicio, a diferencia de Brasil, que en muchos de los documentos oficiales se decanta por el uso de formación docente continuada, y de Argentina, donde prevalece el concepto de formación docente permanente. DINIZ-PEREIRA; J. E. (2010: CD Room) establece un análisis sobre la adopción del término de formación continuada, en Brasil:

É importante frisar, no entanto, que em função das especificidades da educação brasileira, os termos "formação pré-serviço" e "formação em serviço" - traduzidos e adotados acriticamente a partir das expressões em inglês "preserviceteachereducation" e "in-serviceteachereducation" - são bastante inapropriados por não se adequarem à realidade de várias regiões do Brasil, pois, como se sabe, existe ainda, no país, um grande contingente de pessoas que, ao ingressar em um curso ou programa de formação docente, em uma instituição de ensino superior, já atua no magistério há vários anos. A chamada "formação continuada" tornou-se, então, uma expressão bastante conhecida no Brasil, a partir dessa época.(DINIZ-PEREIRA, 2010, CD Room).

Conforme a los documentos oficiales, Argentina, Brasil y Paraguay presentan en sus textos diferentes concepciones para pensar la formación docente desde el contexto intercultural.

$8 \quad$ Enlace: $\quad$ http://www.oei.org.py/index.php/especializaciones-en-educacion-intercultural-bilingue-y-eneducacion-de-personas-jovenes-y-adultas-2/ Fecha de consulta: 30 de diciembre de 2017 
Ello se debe a los diferentes procesos históricos vivenciados por estos tres países y a los diferentes momentos en los que estos documentos se produjeron.

En el caso de Brasil parece asociarse el concepto de interculturalidad con el de una diversidad más plural, mientras que Argentina concibe el término desde una perspectiva que apunta a pensar a una interculturalidad para el diálogo, como valor de la sociedad.

Paraguay es de los tres países el que más ha invertido en una política lingüística y el único que tiene como idioma oficial una lengua indígena, el guaraní.

Brasil ha avanzado en políticas públicas para la diversidad, sin embargo, aún está muy presente la concepción de un país monocultural y monolingüe, idea reafirmada en la actualidad en diversas reformas en el plano educativo.

Cabe destacar que no resulta suficiente la mera formulación de políticas públicas enfocadas a pensar el contexto intercultural, sino que deben ir acompañadas de acciones de formación docente permanente y de una mejora en las condiciones de trabajo.

\section{CONCLUSIÓN}

El siguiente artículo apenas expone de manera descriptiva algunos de los documentos oficiales referidos a los temas que atraviesan la educación y de manera especial, la educación intercultural.

Paraguay, luego de la Reforma Educativa, en 1992, apostó a políticas interculturales y plurilingües. Aunque para MELIA (2012) tanto cuando hablamos de interculturalidad en Paraguay como de bilingüismo, es una farsa. En primer lugar, porque en lo que se refiere a las lenguas, siempre hay una relación de diglosia, donde una lengua tiene más prestigio que otra, relación que se establece entre el castellano y el guaraní.

En Brasil, el término interculturalidad aparece en los documentos elaborados en el año 2016, precisamente en el mes de enero, período de la Presidencia de Dilma Rouseff, dando énfasis a la enseñanza intercultural y bilingüe, si bien la interculturalidad es asociada a las comunidades indígenas. En el concepto de diversidad, las políticas y documentos oficiales analizados parecen englobar más categorías, como género, raza, religión, por ejemplo.

En Argentina, hay una tendencia a denominar políticas para la interculturalidad y ya no para la diversidad, propuesta desde el territorio. Así como apunta, SORIA (2010) también es importante preguntarse si este tipo de políticas educativas que apuntan a lo intercultural, sostienen, aún, las condiciones que producen y reproducen desigualdades. 


\section{REFERENCIAS}

ARGENTINA:

Ley

de

Educación

Nacional,

2006.

Disponible:<https://www.fmmeducacion.com.ar/wp-content/uploads/2018/03/Ley-26026-de-

Educacion-Nacional.pdf> Fecha de consulta: 02 de enero de 2018.

BRASIL. Secretaria de Educação Fundamental. Parâmetros curriculares nacionais: introdução aos parâmetros curriculares nacionais / Secretaria de Educação Fundamental. - Brasília: MEC/SEF, 1997. 126p.

BRASIL: Diretrizes Curriculares Nacionais Gerais da Educação Básica/ Ministério da Educação. Secretária de Educação Básica. Diretoria de Currículos e Educação Integral. Brasília: MEC, SEB, DICEI, 2013.

CANDAU, Ferrão Vera Maria (Org.). Culturas e educação: entre o crítico e o póscrítico. - Rio de Janeiro: DP\&A, 2005.

Educação Intercultural na América Latina: entre concepções, tensões e propostas. - Rio de Janeiro: Letras, 2009.

CANEN, Ana. Educação Multicultural, Identidade Nacional e Pluralidade Cultural: tensões e implicações curriculares. Cadernos de Pesquisa, no. 102, p. 135-150, 2000.

DINIZ-PEREIRA, Julio, Emilio: Formação continuada de professores, DICIONÁRIO: trabalho, profissão e condição docente. Belo Horizonte: UFMG/Faculdade de Educação, 2010. CDROM.

DUBET, François. Mutacionesinstitucionales y/o liberalismo? Revista Colombiana de Sociología, $n^{\circ 25,} 2015$

FLEURI, Reinaldo. Ser democrático não significa apenas deixar ao outro falar, mas entender o que ele tem a dizer. Entrevista. In: A página da educação, año XIII, no139, noviembre de 2004, en línea: https://repositorio.ufsc.br/handle/123456789/185042 Fecha de consulta: 10 de marzo de 2016.

GATTI, Bernadete Angelina. Formação de professores, complexidade e trabalho docente. Revista Diálogo Educacional, Curitiba, v. 17, n. 53, p. 721-737, 2017. En línea:

<https://periodicos.pucpr.br/index.php/dialogoeducacional/article/viewFile/8429/17739

Fecha de consulta: 10 de mayo de 2018.

MELIA, Bartomeu: La interculturalidad y la farsa del bilingüismo. Revista Abehache, $\mathrm{n}^{\circ} 2$, 2012.

TANURI, Leonor Maria. História da formação de professores. Revista Brasileira de Educação, Mai/Jun/Jul/Ago $2000 \quad №$ 14, en línea. Disponible: http://www.scielo.br/pdf/rbedu/n14/n14a05 Fecha de consulta: 25 de diciembre de 2017.

SAFORCADA, Fernanda and VASSILIADES, Alejandro. Las leyes de educación en los comienzos del siglo XXI: del neoliberalismo al postconsenso de Washington en América del Sur. Educ. Soc. [online]. 2011, vol.32, n.115, pp.287-304. 
SORIA, Ana Sofía Intercultural y educación en Argentina: los alcances del reconocimiento, in: Andamios, Volumen 7, №13, México, 2010. En línea: http://www.scielo.org.mx/scielo.php?script=sci arttext\&pid=S1870-00632010000200008 Fecha de consulta: 03 de diciembre de 2016 